\title{
Evaluation Method of Communication Network Based on Reliability Index
}

\author{
Mingjun Zhao, Limin Cui and Mengyao Wang \\ State Grid Xinjiang Information and Telecommunication Company, Urumqi, Xinjiang, China
}

\begin{abstract}
The communication network is becoming more sophisticated. To effectively evaluate the reliability of the communication network was a difficult task in the research of smart grid. In this paper, we propose an index model consisting of three indexes responding to communication network reliability. We can evaluate the communication network from three aspects: communication network topology, equipment health level and network performance. This method can help network managers evaluate the network reliability and provide guidance for communication Network investment.
\end{abstract}

Keywords-communication network evaluation; reliability index; topological index; health index; performance index

\section{INTRODUCTION}

The communication network in the smart grid is becoming more sophisticated, and the requirements for the network reliability are increasing. Liang Xiongjian ${ }^{[1]}$ et al. systematically expounded the theory of communication network reliability. Zhao Ziyan ${ }^{[2]}$ analyzed the establishment of the reliability layered architecture of the power communication network, explained the establishment of communication network malfunctions, reliability measurement and evaluation methods and the establishment of a reliability evaluation system. Pan Yong ${ }^{[3]}$ discussed the survivability, effectiveness, completeness index and their main measures methods, and discussed the reliability index of military communication network in wartime. Gao Huisheng ${ }^{[4]}$ analyzed the composition and service types of the power communication network and defined the reliability requirements for various types of services. By comparing the four measurements: reliability, validity, survivability and security, Gao Huisheng selected the validity as the reliability index of electric power communication network. Zeng Ying ${ }^{[5]}$ et al. proposed a method based on structural entropy to evaluate the reliability of power ICT communication network, based on this, the reliability development trend can be obtained, which provides information for the development planning of power communication network. Fan Bing ${ }^{[6]}$ et al. proposed a vulnerability analysis method for power communication network service layer based on service priorities, and analyzed the vulnerability of four link malfunctions models. Reference [7] builds a complete index evaluation system for the power information and communication system in aspects of safety management system, construction management, dispatch and transportation inspection management, information system security protection, communication systems and equipment, information communication room and power supply facilities, and emergency management. By means of comprehensive diagnosis and evaluation, they find out the hidden dangerous point and weak link of safety.

However, with the increasing size of the network, a large number of nodes and links make the network structure evolve from simple chain, star, ring to complex mesh, and the environment of the network is changing all the time. As a result, the communication network evaluation is becoming more and more complex, the evaluation standard is difficult to unify, and the calculation amount of index increases exponentially.

In order to evaluate the reliability of complex network efficiently and accurately, this paper propose a simple model using key objective indexes, and a method to calculate the reliability index which can reflect the relative change. This paper provides a new idea for the reliability research of complex network.

\section{NETWORK RELIABILITY INDEX}

Reliability is defined as the ability of a product to perform a specified function under specified condition and within a specified period of time. The reliability of communication network is defined in [8] as the ability of communication network to fulfill the normal communication requirements in the process of continuous operation. User needs and network size are constantly changing, so is the reliability of communications networks. For a network of 100 nodes and a network of 200 nodes (the reliability of a single node is the same), the network reliability may be different. For a specific network, the life of the equipment is a function of time. The reliability varies with time.

Reliability is a probability function, which reflects the relative efficiency of the system. A system reliability of 0.99 does not mean that the system will certainly fail for one hour after 100 hours of operation. It only indicates that the system may have failed within 100 hours, and the probability of this failure is 0.01 . And the fault probability occurs under the specified condition, and if the condition changes, the fault probability will change. In fact, the operating environment of the system varies widely, and the types of equipment are various. It is difficult to accurately evaluate the reliability of the network, even if the operating environment of the system and the failure rate of each device are known. The complicated connection relationship between devices cannot be accurately expressed by mathematical model, which leads to the reliability evaluation of complex network is difficult to quantify.

Index method is an important statistical method to analyze the quantity change of social economic phenomenon, and we can utilize it in the reliability evaluation of complex networks, 
on the one hand, it can effectively solve the problem of the same quantization of different measurement units in evaluation, on the other hand, it is convenient to observe the total variation degree of reliability in different time; the most important thing is that the trend of changes in the index is consistent with the trend of changes in reliability. This inspired us to observe the reliability growth of the network over a long period of time by setting a fixed-base index.

Complex network composed of a large number of nodes and links. The more reliable the nodes and links are, the more reliable and stronger the network is. Network bandwidth is also important to meet the needs of user. This can be shown in figure 1.

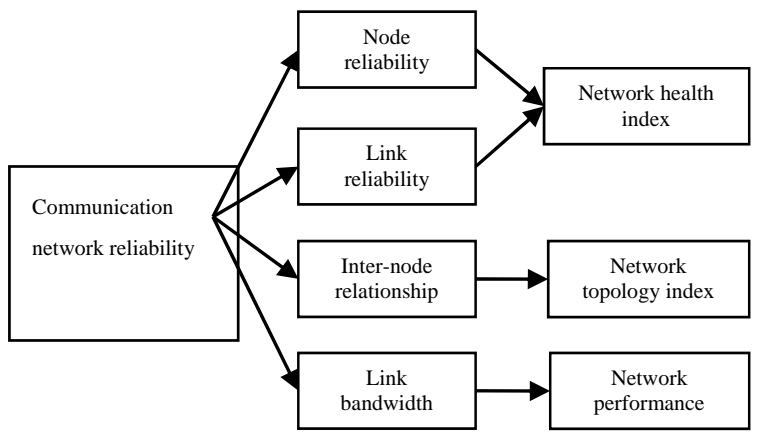

\section{FIGURE I. KEY FACTORS OF COMMUNICATION NETWORK RELIABILITY}

The important indexes are network topology index, equipment health index and network performance index. Through the index variation, the index model can reflect the whole development trend of the network. We define that, network topology index is $R_{1}$, network health index is $R_{2}$ and network performance index is $R_{3}$. The network health index $R_{2}$ can be further divided into node health index $R_{21}$ and link health index $\mathrm{R}_{22}$. The reliability index $\mathrm{R}_{0}$ of the communication network can be easily calculated as follow:

$$
\mathrm{R}_{0}=\mathrm{a}_{1} \mathrm{R}_{1}+\mathrm{a}_{2} \mathrm{R}_{2}+\mathrm{a}_{3} \mathrm{R}_{3}
$$

where $\mathrm{a}_{1}+\mathrm{a}_{2}+\mathrm{a}_{3}=1$.

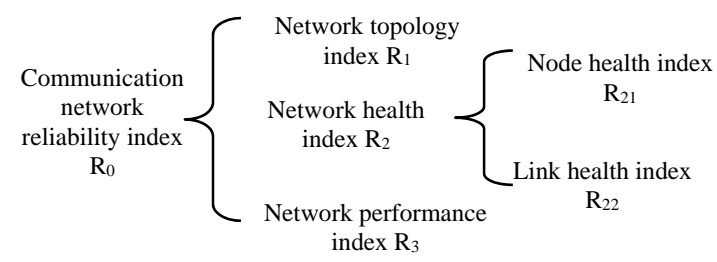

\section{FIGURE II. DIAGRAM OF RELIABILITY INDEX OF} COMMUNICATION NETWORK

\section{A. Network Topology Index}

Typical network structure includes line, tree, star, ring and mesh. For a network with $\mathrm{n}$ nodes and $\mathrm{m}$ lines, the network topology index R1 is calculated as follows:

Firstly, we can get the topological complexity r1:

$$
\mathrm{r}_{1}=\frac{\sum_{\mathrm{i}=1}^{\mathrm{n}} \mathrm{d}_{\mathrm{i}}}{\mathrm{n}}
$$

where $d_{i}$ represents the degree of node $i$.

According to graph theory, the sum of degrees of network nodes is equal to 2 times of lines, so (2) can also be expressed as:

$$
\mathrm{r}_{1}=\frac{2 \mathrm{~m}}{\mathrm{n}}
$$

The more complex the network topology is, the larger the value of $r_{1}$ and the higher the network reliability is. For line, tree, and star networks, the number of lines is one less than the number of nodes, and the topology complexity is $2(n-1) / n$. For a ring network (including one ring with multiple links), the number of lines is the same as the number of nodes, thus the topology complexity is 2. Mesh network is divided into incomplete mesh and fully connected mesh network. In fully connected mesh, there is a direct route between any two nodes, thus $m=n(n-1) / 2$, the topology complexity is $(n-1) / 2$.

The communication network is the hybrid complex network, and its topology complexity is greater than the ring network (complexity is 2) and less than the complete network (complexity is (n-1)/2).

We define the topological complexity of initial year is $r_{1}^{(0)}$, the topological complexity of the first year is $r_{1}^{(1)}$, the topological complexity of the second year is $r_{1}^{(2)}$, ect. We can get the network topology index $\mathrm{R}_{1}$ :

$$
\mathrm{R}_{1}^{(\mathrm{i})}=\frac{\mathrm{r}_{1}^{(\mathrm{i})}}{\mathrm{r}_{1}^{(0)}} * 100
$$

where $\mathrm{i}=0,1,2 \ldots$

\section{B. Network Health Index}

The network health index $R_{2}$ is a weighted value of the node health index $\mathrm{R}_{21}$ and the link health index $\mathrm{R}_{22}$.

$$
R_{2}=\beta_{1} R_{21}+\beta_{2} R_{22}
$$

where $\beta 1+\beta 2=1$

Communication Network is composed of a large number of nodes and links, each node or each link represent a specific device, each device has its own lifetime. As time goes by, the health index of the equipment decline monotonously. How about the network? The health index of the network may increase by renewing of the equipment or expanding the network. For a fixed sized network, the health of the network will increase only if the updating rate exceeds its natural attenuation rate. For the expanding network, the increase rate of new nodes and links exceeds the natural attenuation rate of the network, and the health of the network will surely increase.

As we know, the life cycle of communication equipment is subject to exponential distribution, the natural attenuation of the network is also subject to exponential distribution. Assume that the natural attenuation rate of the network is $b$, the initial 
health of the network is 1 , the number of new nodes is $V_{\text {new }}$, the number of new links is $E_{\text {new }}$, the number of renewed nodes is $\mathrm{V}_{\text {renewed, }}$ and the number of modified links is $\mathrm{E}_{\text {renewed. }}$ Then index $r_{2}$ is:

$$
\mathrm{r}_{2}=1+\frac{\left(V_{\text {new }}+V_{\text {renewed }}+E_{\text {new }}+E_{\text {renewed }}\right)}{n+m}-b
$$

where $\mathrm{t}=1,2,3 \ldots$

Network health for the initial year is $r_{2}^{(0)}$, the first year of network health is $r_{2}^{(1)}$, for the second year, the network health $\operatorname{isr}_{2}^{(2)}$,ect. We get the network health index $R_{2}$.

$$
\mathrm{R}_{2}^{(\mathrm{i})}=\frac{\mathrm{r}_{2}^{(\mathrm{i})}}{\mathrm{r}_{2}^{0}} * 100
$$

where $\mathrm{i}=0,1,2 \ldots$

\section{Network Performance Index}

The network performance indexes include error rate, delay, jitter, bandwidth, etc. However, with the development of technology, The impact of the error rate, delay and jitter is trivial. With the increasing demand of bandwidth, the network bandwidth has become the most critical factor. Thus, the network bandwidth index can be used to represent the network performance. Firstly, we can calculate the average bandwidth $r_{3}$ as follow.

$$
\mathrm{r}_{3}=\frac{\sum_{\mathrm{j}=1}^{\mathrm{m}} \mathrm{B}_{\mathrm{j}}}{m}
$$

where $B_{j}$ represent the bandwidth of link $j$.

Network performance of initial year is $r_{3}^{(0)}$, the network performance of first year is $r_{3}^{(1)}$, the network performance of the second year is $r_{3}^{(2)}$, etc. Finally we get the network performance index $\mathrm{R}_{3}$.

$$
\mathrm{R}_{3}^{(\mathrm{i})}=\frac{\mathrm{r}_{3}^{(\mathrm{i})}}{\mathrm{r}_{3}^{(0)}} * 100
$$

where $\mathrm{i}=1,2,3 \ldots$

\section{EXAMPLE ANALYSIS OF COMMUNICATION NETWORK EVALUATION}

The data of a communication network during "11th fiveyear plan" and "twelfth five-year plan" are shown in Table I.

The topological index of the network can be calculated by (3) and (4). The initial topological complexity of the network is 2.4 , and the initial network topology index is 100 . At the end of the eleventh five-year, the network topology index reached to 104.798 , with an average annual growth rate of about $1 \%$. At the end of the 12th five-year plan, the network topology index was 129.4129 , with an average annual growth rate of about $4 \%$. This is shown in FIGURE 3.It indicates that, during "eleventh five-year plan", the reliability of network topology has increased by $23.49 \%$ compared with the " 12 th five-year plan" period.
TABLE I. STATISTICS DURING "11TH FIVE-YEAR PLAN" AND

\begin{tabular}{|c|c|c|c|c|c|}
\hline Year & 6 & 7 & 8 & 9 & 10 \\
\hline $\begin{array}{c}\text { Number of } \\
\text { nodes }\end{array}$ & 227 & 261 & 300 & 345 & 396 \\
\hline $\begin{array}{l}\text { Number of } \\
\text { lines }\end{array}$ & 298 & 357 & 428 & 513 & 615 \\
\hline $\begin{array}{l}\text { Number of } \\
\text { renewed } \\
\text { nodes }\end{array}$ & 11 & 13 & 15 & 17 & 5 \\
\hline $\begin{array}{l}\text { Number of } \\
\text { renewed lines }\end{array}$ & 14 & 17 & 21 & 25 & 6 \\
\hline $\begin{array}{l}\text { Number of } \\
\text { new nodes }\end{array}$ & 34 & 39 & 45 & 51 & 15 \\
\hline $\begin{array}{c}\text { Number of } \\
\text { new links }\end{array}$ & 59 & 71 & 85 & 102 & 19 \\
\hline $\begin{array}{c}\text { Number of } \\
622 \mathrm{Mb} / \mathrm{s}\end{array}$ & 0 & 0 & 0 & 0 & 0 \\
\hline $\begin{array}{c}\text { Number of } \\
2.5 \mathrm{~Gb} / \mathrm{s}\end{array}$ & 258 & 297 & 348 & 413 & 495 \\
\hline $\begin{array}{c}\text { Number of } \\
10 \mathrm{~Gb} / \mathrm{s}\end{array}$ & 40 & 60 & 80 & 100 & 120 \\
\hline
\end{tabular}
"TWELFTH FIVE-YEAR PLAN" OF A REGIONAL COMMUNICATION NETWORK

\begin{tabular}{c|c|c|c|c|c|c}
\hline Year & $\mathbf{0}$ & $\mathbf{1}$ & $\mathbf{2}$ & $\mathbf{3}$ & $\mathbf{4}$ & $\mathbf{5}$ \\
\hline $\begin{array}{c}\text { Number of } \\
\text { nodes }\end{array}$ & 100 & 115 & 132 & 151 & 173 & 198 \\
\hline $\begin{array}{c}\text { Number of } \\
\text { lines }\end{array}$ & 120 & 139 & 161 & 186 & 215 & 249 \\
\hline $\begin{array}{c}\text { Number of } \\
\text { renewed } \\
\text { nodes }\end{array}$ & 5 & 5 & 6 & 7 & 8 & 9 \\
\hline $\begin{array}{c}\text { Number of } \\
\text { renewed } \\
\text { lines }\end{array}$ & 6 & 6 & 8 & 9 & 10 & 12 \\
\hline $\begin{array}{c}\text { Number of } \\
\text { new nodes }\end{array}$ & 15 & 17 & 19 & 22 & 25 & 29 \\
\hline $\begin{array}{c}\text { Number of } \\
\text { new links }\end{array}$ & 19 & 22 & 25 & 29 & 34 & 49 \\
\hline $\begin{array}{c}\text { Number of } \\
\mathbf{6 2 2 M b}\end{array}$ & 120 & 90 & 60 & 30 & 0 & 0 \\
\hline $\begin{array}{c}\text { Number of } \\
\text { 2.5Gb/s }\end{array}$ & 0 & 49 & 101 & 156 & 215 & 229 \\
\hline $\begin{array}{c}\text { Number of } \\
\text { 10Gb/s }\end{array}$ & 0 & 0 & 0 & 0 & 0 & 20 \\
\hline
\end{tabular}

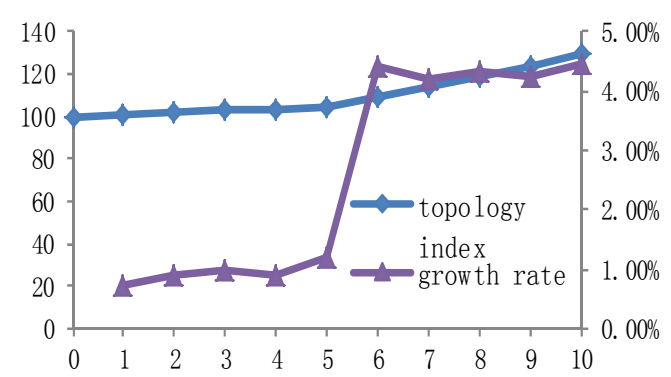

FIGURE III. HISTORICAL DATA GRAPH OF NETWORK TOPOLOGY INDEX

The network health index calculation is relatively more complex and needs to determine the life functions of all equipment. In order to simplify the calculation process, we assumed that all life functions in this system are the same one, and is subject to exponential distribution: $f(t)=0.95 t$, where $t$ dedicate the number of years of the device. Using (6) and (7), 
the corresponding network health index can be calculated, and is shown in FIIGURE 4.

According to FIGURE 4, the health level of the network maintained a steady growth rate over the past 10 years, which has doubled from 100 to 205.6345. However, the growth rate fluctuates a lot (between $4 \%$ and 12\%), and the growth rate declines year by year, indicating slow updating speed of the network.

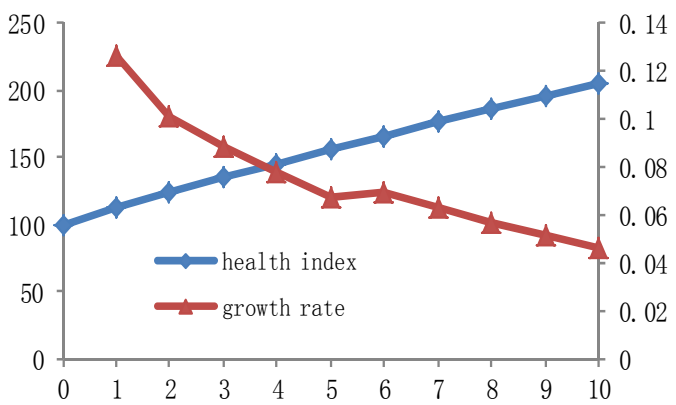

FIGURE IV. HISTORICAL DATA GRAPH OF NETWORK HEALTH INDEX

Similarly, the network performance indexes can be calculated using (8) and (9), and are shown in FIGURE 5.

During "the eleventh five-year plan" and "twelfth five-year plan", the performance index of the communication network increased more than six times from 100 to 637.2 to be consistent with the rapid increase demand of bandwidth. However, the growth rate of network performance fall fast during "twelfth five-year", in last two years it is almost zero. It indicate that: in recent two years, the network bandwidth explosion work is not effective, this may lead to rapid decline in redundancy of network bandwidth, even worse, dilemma of insufficient capacity .

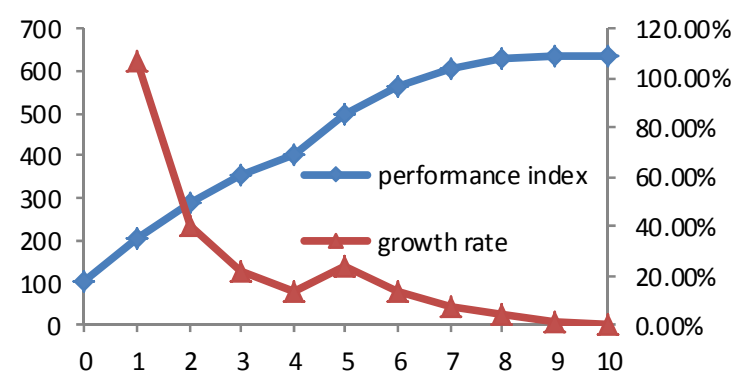

\section{FIGURE V. HISTORICAL DATA GRAPH OF NETWORK} PERFORMANCE INDEX

According to topological index, health index and performance index, the reliability index of the communication network can be calculated by (1), where $\mathrm{a}_{1}=\mathrm{a}_{2}=0.4, \mathrm{a}_{3}=0.2$. The data are shown in FIGURE6.

The overall reliability of the network has increased during "the eleventh five-year plan" and "the 12th five-year plan". The reliability index has increased 2.6 times from 100 to 261.4625 .
But the network reliability growth rate fluctuated greatly between $6 \%$ and $26 \%$.

During "11th five-year", the reliability index doubled from 100 to 203.83, the network reliability has improved. The reliability growth rate decreased and has a little peak in the fifth year, this is mainly contribute to $622 \mathrm{M}$ to $2.5 \mathrm{G}$ network renovation in first year and $2.5 \mathrm{G}$ to $10 \mathrm{G}$ network renovation in the fifth year.

In "Twelfth five-year" period, the network reliability index overall increased 30\% from 203.83 to 261.46. However reliability growth rate reduced year by year. At the end of the twelfth five-year, growth rate has fallen to $2.3 \%$ and reached to the lowest point. Compared with "11th five-year plan", the topological index average growth rate increased from $1 \%$ to $4 \%$, health index average growth rate decreased from $9 \%$ to $6 \%$,the growth rate of the performance index decrease from $41 \%$ to $5 \%$. It is shown that the network performance index is the key factor to the decline in growth of network reliability. The network bandwidth in this area has not met the demand of users. This further proves the validity of evaluation method based on reliability index.

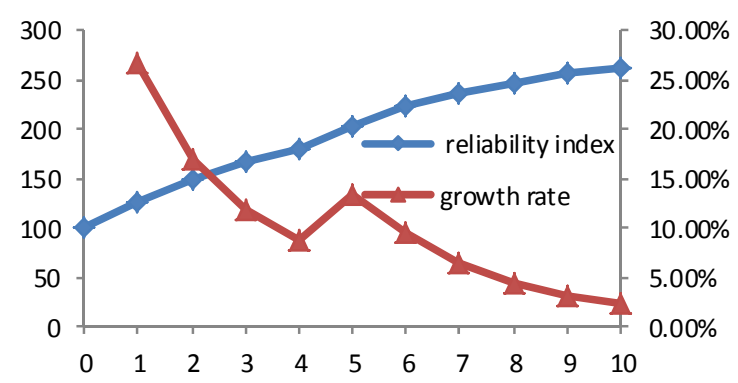

FIGURE VI. HISTORICAL DATA GRAPH OF NETWORK RELIABILITY INDEX.

\section{CONCLUSION}

Communication network is an important part of smart grid. Evaluation method based on reliability index can help network managers evaluate the network reliability, network survivability, equipment upgrades and network bandwidth condition, and find out shortcomings. Furthermore, this method also provides the guidance for the communication network planning: the manager can compare the annual reliability index with the annual investment of the communication network and evaluate the effect of the investment.

\section{REFERENCES}

[1] Liang Xiongjian, Sun Tsinghua. Reliability management of communication network [M]. [Beijing]: [Beijing University of Posts and Telecommunications press], 2004

[2] Zhao Ziyan, Chen Xi, Liu Jianming. Establishment of reliability management system of power system communication network. The communication of [J]. power system, 2006 (10): 58-61.

[3] Pan Yong. Reliability index of communication network research on reliability and environmental testing of [J]. electronic products, 2006 (1): 1-5.

[4] Gao Huisheng. Reliability study of power communication network [D]. North China Electric Power University (Hebei), 2009. 
[5] Ceng Ying, Zhu Wenhong. Evaluation method for reliability of power ICT communication networks based on the structure entropy weight method [J]. East China power, 2014 (1): 97-100.

[6] Fan Bing, Tang Liangrui. Vulnerability analysis of electric power communication network [J]. Chinese Journal of electrical engineering, 2014 (7): 1191-1197.

[7] China State Grid Corp. Information and communication security evaluation of China State Grid Corp: 2015 version of [M]. Beijing: China Electric Power Press, 2015

[8] Liu Youheng, Xiong Wei Ming, Li Xianyu. Study on network reliability measure [J]. computer and network communication, 1989 (1): 172-176. 